\title{
Spectrum of changes in anogenital mammary-like glands in primary extramammary (Anogenital) paget disease and their possible role in the pathogenesis of the disease
}

Konstantinova, Anastasia M ; Spagnolo, Dominic V ; Stewart, Colin J R ; Kacerovska, Denisa ; Shelekhova, Ksenya V ; Plaza, Jose A ; Suster, Saul ; Bouda, Jiri ; Kyrpychova, Liubov ; Michal, Michal ; Belousova, Irena E ; Kerl, Katrin ; Kazakov, Dmitry V

\begin{abstract}
To determine whether a subset of primary extramammary Paget disease (EMPD) may originate in anogenital mammary-like glands (AGMLG), the authors studied 181 specimens of EMPD, detailing alterations in AGMLG. The latter were identified in 33 specimens from 31 patients. All patients were women, ranging in age from 38 to 93 years (median, 65 y). In all cases, lesions involved the vulva and in 1 patient the perianal skin was affected. Histopathologically, AGMLG manifested changes identical to columnar cell change (CCC) $(87.1 \%)$, usual ductal hyperplasia $(22.6 \%)$, columnar cell hyperplasia $(\mathrm{CCH})(9.7 \%)$, oxyphilic (apocrine) metaplasia (6.5\%), and atypical duct hyperplasia (3.2\%). Four cases $(12.9 \%)$, in addition to intraepidermal carcinoma, harbored invasive carcinoma. In all 4 of these, AGMLG displayed a range of alterations including ductal carcinoma in situ, CCC, and CCH. Three further cases $(9.7 \%)$ showed ductal carcinoma in situ without any definite invasive carcinoma. Colonization of AGMLG by neoplastic Paget cells was noted in 6 cases. As CCC and CCH may be encountered in normal AGMLG, these alterations are unlikely to play a significant role in the pathogenesis of the disease. However, by analogy with mammary Paget disease, rare cases of primary EMPD may originate in AGMLG with a subsequent upward migration of the neoplastic cells into the epidermis and possible later breach through the basal membrane. Usual ductal hyperplasia and atypical duct hyperplasia can then be regarded as earlier precursor lesions, linking both ends of the spectrum.
\end{abstract}

DOI: https://doi.org/10.1097/PAS.0000000000000857

Posted at the Zurich Open Repository and Archive, University of Zurich

ZORA URL: https://doi.org/10.5167/uzh-142498

Journal Article

Published Version

Originally published at:

Konstantinova, Anastasia M; Spagnolo, Dominic V; Stewart, Colin J R; Kacerovska, Denisa; Shelekhova, Ksenya V; Plaza, Jose A; Suster, Saul; Bouda, Jiri; Kyrpychova, Liubov; Michal, Michal; Belousova, Irena E; Kerl, Katrin; Kazakov, Dmitry V (2017). Spectrum of changes in anogenital mammary-like glands in primary extramammary (Anogenital) paget disease and their possible role in the pathogenesis of the disease. American Journal of Surgical Pathology, 41(8):1053-1058.

DOI: https://doi.org/10.1097/PAS.0000000000000857 


\title{
Spectrum of Changes in Anogenital Mammary-like Glands in Primary Extramammary (Anogenital) Paget Disease and Their Possible Role in the Pathogenesis of the Disease
}

\author{
Anastasia M. Konstantinova, MD, PhD, *† Dominic V. Spagnolo, MBBS, FRCPA, $\S \|$ \\ Colin J.R. Stewart, FRCPA, $\uparrow$ Denisa Kacerovska, MD, PhD,\#** Ksenya V. Shelekhova, MD, PhD,* \\ Jose A. Plaza, MD,†† Saul Suster, MD, \$† Jiri Bouda, MD, PhD, §\& Liubov Kyrpychova, MD,\# \\ Michal Michal, MD,\#** Irena E. Belousova, MD, PhD,* ${ }^{*}\|\|$ Katrin Kerl, MD, 99 \\ and Dmitry V. Kazakov, MD, PhD\# 99
}

\begin{abstract}
To determine whether a subset of primary extramammary Paget disease (EMPD) may originate in anogenital mammary-like glands (AGMLG), the authors studied 181 specimens of EMPD, detailing alterations in AGMLG. The latter were identified in 33 specimens from 31 patients. All patients were women, ranging in age from 38 to 93 years (median, $65 \mathrm{y}$ ). In all cases, lesions involved the vulva and in 1 patient the perianal skin was affected. Histopathologically, AGMLG manifested changes identical to columnar cell change (CCC) (87.1\%), usual ductal hyperplasia (22.6\%), columnar cell hyperplasia $(\mathrm{CCH})(9.7 \%)$, oxyphilic (apocrine) metaplasia $(6.5 \%)$, and atypical duct hyperplasia (3.2\%). Four cases $(12.9 \%)$, in addition to intraepidermal carcinoma, harbored invasive carcinoma. In all 4 of these, AGMLG displayed a range of alterations including ductal carcinoma in situ, $\mathrm{CCC}$, and $\mathrm{CCH}$. Three further cases $(9.7 \%)$ showed ductal carcinoma in situ without any definite invasive carcinoma. Colonization of AGMLG by neoplastic Paget
\end{abstract}

From the *Department of Pathology, Clinical Research and Practical Center for Specialized Oncological Care; $†$ Department of Pathology, Medical Faculty, Saint-Petersburg State University; $₫$ Department of Pathology, Saint-Petersburg Medico-Social Institute; || || Department of Dermatology, Medical Military Academy, Saint Petersburg, Russia; §PathWest Laboratory Medicine WA, QEII Medical Centre; $\|$ School of Pathology and Laboratory Medicine, University of Western Australia, Nedlands; PathWest Laboratory Medicine WA, King Edward Memorial Hospital, Perth, WA, Australia; \#Sikl's Department of Pathology, Medical Faculty in Pilsen, Charles University in Prague; **Bioptical Laboratory; §§Department of Obstetrics and Gynecology, Charles University Medical Faculty Hospital, Pilsen, Czech Republic; $\dagger \dagger$ Miraca Life Science, Irving, TX; †tDepartment of Pathology, Division of Dermatopathology, Medical College of Wisconsin, Milwaukee, WI; and $\uparrow$ Dermatopathology Unit, Department of Dermatology, Zurich University Hospital, Zurich, Switzerland.

Supported in part by the SVV project 260391.

Presented in part at the annual meeting of the United States and Canadian Academy of Pathology, San Antonio, TX, March 4 to 10, 2017.

Conflicts of Interest and Source of Funding: The authors have disclosed that they have no significant relationships with, or financial interest in, any commercial companies pertaining to this article.

Correspondence: Dmitry V. Kazakov, MD, PhD, Sikl's Department of Pathology, Charles University Medical Faculty Hospital, Alej Svobody 80, 30460 Pilsen, Czech Republic (e-mail: kazakov@medima.cz).

Copyright (C) 2017 Wolters Kluwer Health, Inc. All rights reserved. cells was noted in 6 cases. As $\mathrm{CCC}$ and $\mathrm{CCH}$ may be encountered in normal AGMLG, these alterations are unlikely to play a significant role in the pathogenesis of the disease. However, by analogy with mammary Paget disease, rare cases of primary EMPD may originate in AGMLG with a subsequent upward migration of the neoplastic cells into the epidermis and possible later breach through the basal membrane. Usual ductal hyperplasia and atypical duct hyperplasia can then be regarded as earlier precursor lesions, linking both ends of the spectrum.

Key Words: anogenital mammary-like glands, extramammary Paget disease, vulva, columnar cell change, columnar cell hyperplasia, ductal hyperplasia, mammary-type carcinoma

(Am J Surg Pathol 2017;41:1053-1058)

Extramammary Paget disease (EMPD) is a rare neoEplasm usually involving the anogenital area, most commonly the vulva. ${ }^{1}$ EMPD can be divided into primary and secondary forms, the latter representing intraepithelial spread of an underlying carcinoma arising in the urogenital or gastrointestinal tracts. ${ }^{2-5}$ The histogenesis of primary EMPD is uncertain. Cutaneous adnexa, clear cells of Toker, pluripotent stem cells, and anogenital mammary-like glands (AGMLG) have been proposed as possible sites of origin. , $^{2-18}$

Unlike in mammary Paget disease (MPD), underlying ductal carcinoma in situ (DCIS) or invasive mammary-type carcinoma are rarely associated with primary EMPD, 2,19-21 but, when present, they raise the likelihood that the pathogenesis of EMPD in these cases may be identical to that of MPD. ${ }^{2}$ In addition to DCIS, AGMLG in cases of primary EMPD may show changes identical to those affecting ducts in the breast, including columnar cell change (CCC), columnar cell hyperplasia $(\mathrm{CCH})$, usual ductal hyperplasia (UDH), and atypical duct hyperplasia (ADH). ${ }^{2,7}$ Further, AGMLG may represent a path for carcinomatous spread into deeper tissues. ${ }^{2,7,22}$

The goals of our study were to identify and describe the spectrum of involvement of AGMLG and their ducts in cases of primary anogenital EMPD, and to determine 
whether a subset of primary EMPD may originate in AGMLG, analogous to breast carcinoma.

\section{MATERIALS AND METHODS}

\section{Case Selection}

A search in the consultation, routine institutional, and personal files of the authors between 1993 and 2016 years yielded 202 cases coded as EMPD. Histologic slides were reviewed along with the available clinical information obtained from patients' medical records to confirm the location and the clinicopathologic context. Only cases of primary anogenital EMPD were included. Excluded from the study were 21 cases of secondary EMPD arising from carcinomas of other primary sites (rectum, urethra, prostate, etc.) and cases with insufficient clinical data.

\section{Light Microscopy}

The study was based on the assessment of hematoxylin and eosin-stained slides. All specimens were local resections, wide surgical excisions, or vulvectomies. We determined the presence and nature of involvement of AGMLG and their ducts in 181 specimens from 150 patients. Of the 181 specimens, 102 were wide surgical excisions, local resections, or vulvectomies (the number of tissue blocks ranged from 1 to 59; median, 10) and 79 were small specimens (punch, or small incisional biopsies, with a single block per case).

The following features were assessed using the same criteria applied in breast pathology ${ }^{23-25}$ : oxyphilic metaplasia, $\mathrm{CCC}, \mathrm{CCH}, \mathrm{UDH}, \mathrm{ADH}, \mathrm{DCIS}$, and colonization of AGMLG by carcinoma cells. Oxyphilic metaplasia manifests as cells with eosinophilic, glassy cytoplasm, which may have mildly pleomorphic nuclei and conspicuous nucleoli. CCC presents as variably dilated lumina lined by 1 to 2 layers of columnar epithelial cells oriented perpendicularly to the basement membrane and which have apical cytoplasmic blebs or snouts. $\mathrm{CCH}$ has variably dilated lumina lined by $>2$ layers of columnar epithelial cells as described for CCC. UDH shows solid or fenestrated intralumimal streaming cellular proliferation without atypia. ADH was defined as a marked intraluminal proliferation of uniform cuboidal epithelial cells with increased nuclear to cytoplasmic ratio, forming complex architectural patterns including micropapillae, true papillae, cribriform spaces with Roman bridges but with mild or no cytologic atypia. ${ }^{2}$ DCIS was defined according to Rosai, including papillary, comedocarcinoma, solid, cribriform, micropapillary, clinging, and cystic hypersecretory variants. ${ }^{23}$ Grading of DCIS of AGMLG was according to published criteria. ${ }^{26}$ For EMPD having both invasive carcinoma and DCIS, grading of the invasive carcinoma was performed according to the Nottingham system (Elston-Ellis modification of Scarff-Bloom-Richardson grading system). ${ }^{25}$

All the specimens were reviewed by a general pathologist (A.M.K.), dermatopathologist (D.V.K.), and an expert in mammary pathology (M.M.). The number of tissue blocks with changes in AGMLG ranged from 1 to 12 (median, 3) per case. All patients were women, ranging in age from 38 to 93 years (median, 65y; mean, 64.2 y). The age of the patients was unknown in 2 cases.

All included patients were the subjects of previous publications addressing various other clinicopathologic aspects of AGMLG and EMPD. 7,22,27-29

\section{RESULTS}

The main clinical and morphologic findings are summarized in Table 1. All lesions involved the vulva other than 1 case of UDH in the perianal skin. Alterations of AGMLG were found in 33 specimens from 31 patients. In 29 cases, the carcinoma was confined to the epidermis (in situ), whereas in the remaining 4 there was stromal microinvasion defined as invasion to a depth of no $>1 \mathrm{~mm} .{ }^{30}$ The most common change encountered in AGMLG was CCC (87.1\%) (Fig. 1). Less frequently found were UDH $(22.6 \%), \mathrm{CCH}(9.7 \%)$, oxyphilic (apocrine) metaplasia (6.5\%), and ADH (3.2\%) (Figs. 2-4). Four cases (12.9\%), in addition to intraepidermal carcinoma, harbored invasive carcinoma resembling breast carcinoma (3 with invasive carcinoma of no special type [NST] [previously known as ductal carcinoma]; 1 with a tubulolobular carcinoma). In all 4 cases AGMLG displayed a range of changes including DCIS ( 1 case), CCC ( 2 cases), and $\mathrm{CCC}$ combined with $\mathrm{CCH}$ (1 case) (Figs. 5, 6). In a further 3 cases $(9.7 \%)$, DCIS without definite invasion was recognized. In 2 of these, adjacent to DCIS were areas of fibrosis and elastosis, as may be found in mammary invasive carcinoma, NST (Fig. 7). DCIS morphology included solid growth with

TABLE 1. Summary of the Main Clinicopathologic Features

\begin{tabular}{lccc}
\hline Type of Change in AGMLG & No. Cases & Other Changes in AGMLG (No. Cases) & Age (y)/Median (Range) \\
CCC & 12 & - & $68(49-86)$ \\
CCH & 2 & CCC (2) & $61(57-65)$ \\
UDH & 5 & CCC (4), OM (1) & $70(59-93)$ \\
DCIS, G2-3 & 3 & CCC (3), AGMLG colonization (1) & $51(40-56)$ \\
ICNST, G3, and DCIS & 1 & CCC (3), CCH (1) & $78(38-78)$ \\
Invasive mammary-type carcinomas, G2-3 incl. & 3 & & $51.5(47-75)$ \\
$\quad$ ICNST (2) and TLC (1) & 5 & CCC (3), UDH (2), ADH (1), OM (1) & Unknown in 1 case \\
Colonization by neoplastic cells & & & \\
\end{tabular}

ICNST indicates invasive carcinoma, no special type (previously known as invasive ductal carcinoma); OM, oxyphilic metaplasia; TLC tubulolobular carcinoma. 

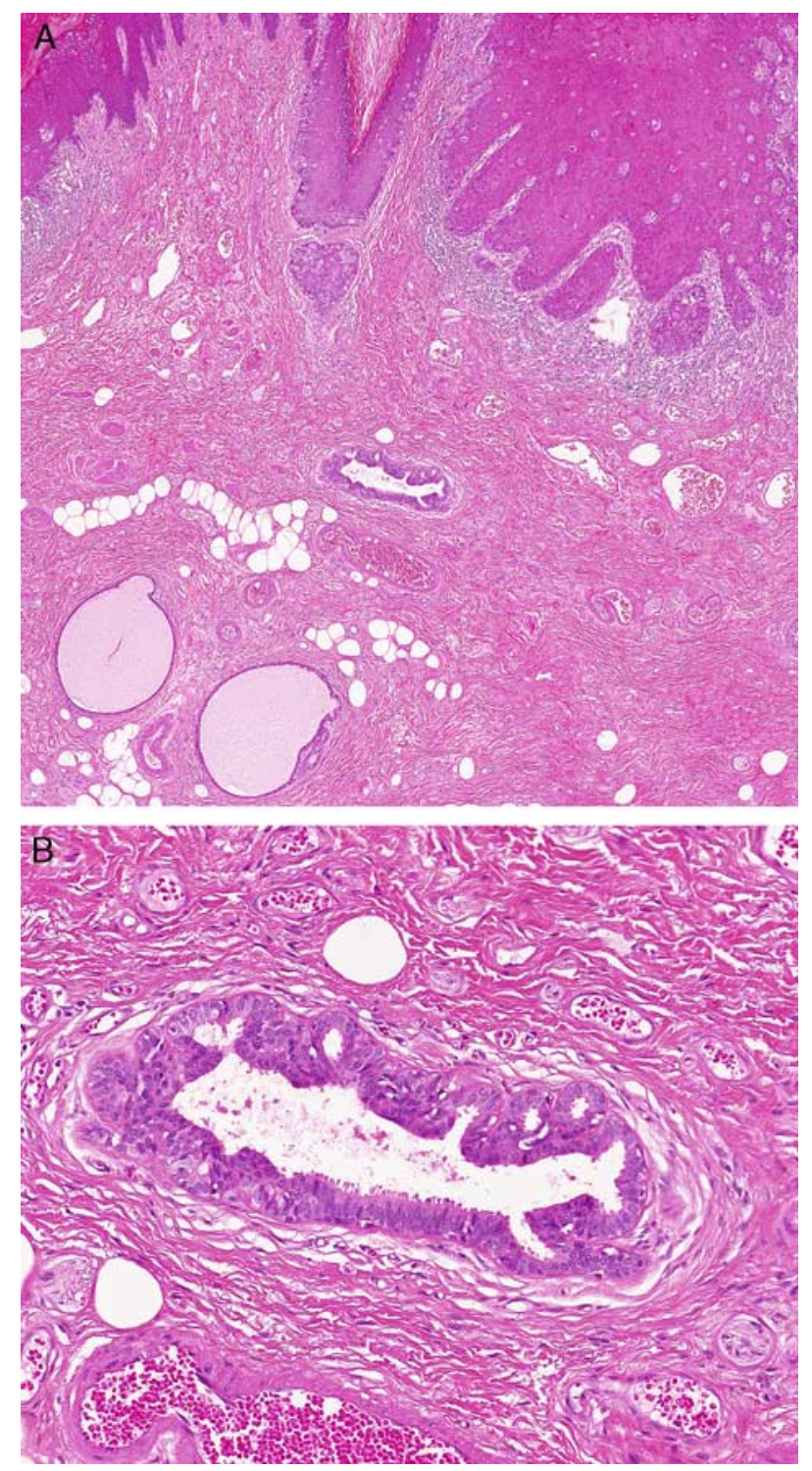

FIGURE 1. $A$ and $B, C C C$ of AGMLG in EMPD. Note a lumen of the gland lined by 1 to 2 cell layers of elongated to ovoid columnar epithelial cells oriented perpendicularly to the basement membrane, having apical cytoplasmic snouts.

or without comedonecrosis or a micropapillary pattern, and was of grade 2 to 3 . The invasive carcinomas also were grade 2 or 3 . Colonization of AGMLG by neoplastic Paget cells was noted in 6 cases (Fig. 8). In 3, single cells or small clusters of neoplastic cells focally infiltrated the glandular portion of AGMLG. One case each, respectively, showed extensive single cell infiltration of neoplastic cells beneath a preserved luminal layer in an excretory duct, similar extensive single cell infiltration in both glandular and excretory duct elements, and almost complete replacement of normal glandular luminal epithelium by solid and cribriform formations of Paget cells, with a preserved peripheral myoepithelial cell layer, occasioning resemblance to DCIS. In a further case with DCIS, there was also extensive colonization of AGMLG.
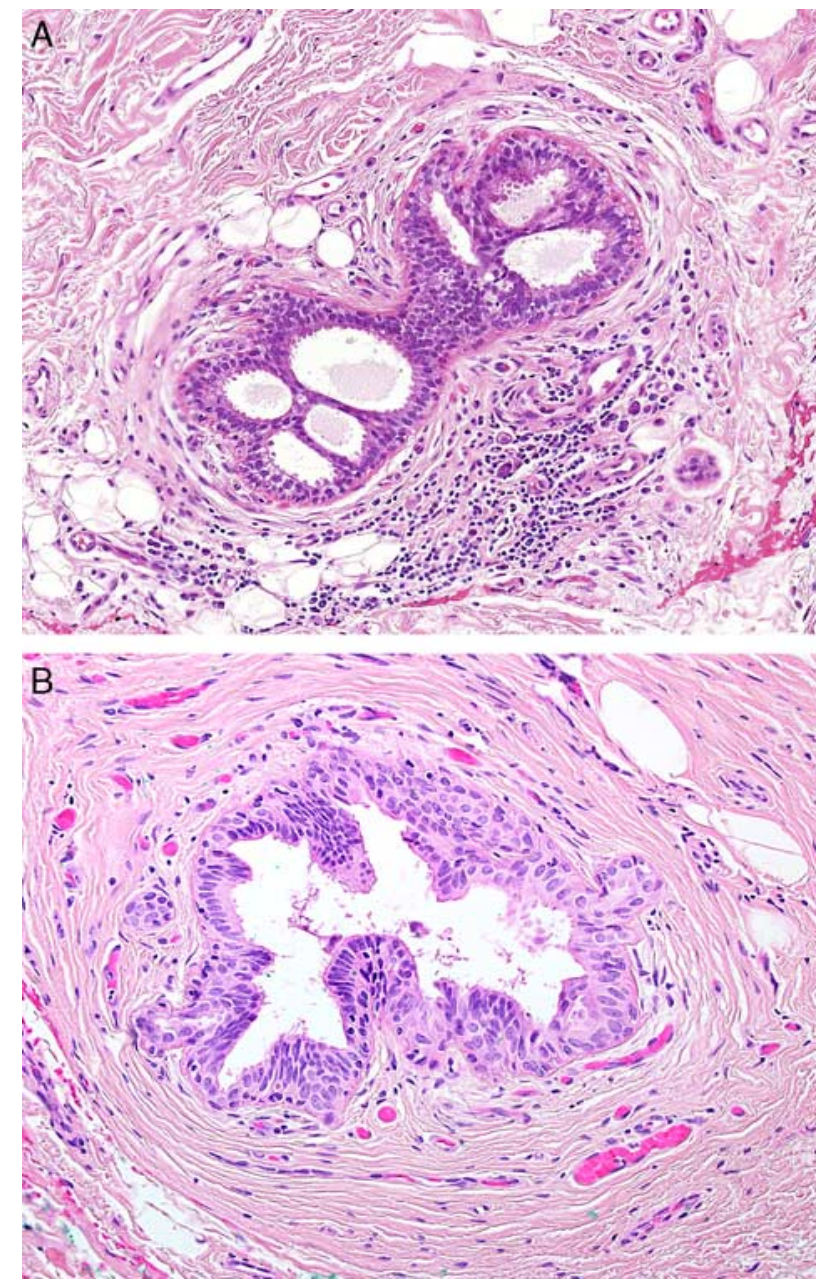

FIGURE 2. UDH of AGMLG showing irregularly shaped bridges connecting opposite portions of the wall $(A)$ or intraluminal proliferations of relatively monomorphic cells (B).

\section{DISCUSSION}

We found alterations of AGMLG in 33 of 181 specimens $(18.2 \%)$ although the actual figure may be higher, as some specimens (small biopsies) lacked AGMLG. From our findings, there seems to be a spectrum of ductal lesions ranging from $\mathrm{CCC}$ and $\mathrm{CCH}$ via $\mathrm{UDH} / \mathrm{ADH}$ to DCIS and invasive carcinoma. The question is whether this finding allows a bona fide conclusion that a subset of primary EMPD may originate in AGMLG. Although in the breast, low level allelic imbalance was demonstrated in columnar cell lesions, ${ }^{31}$ our recent study suggested that $\mathrm{CCC}$ and $\mathrm{CCH}$ may occur normally in AGMLG, as they were seen in approximately $30 \%$ and $10 \%$ of cases, respectively. ${ }^{32}$ Admittedly, no molecular biological studies were carried out for comparison with the breast data. More remarkable is that CCC in AGMLG in the setting of EMPD is much more frequent than in "normal" AGMLG (87\% vs. $33 \%$, respectively). ${ }^{32}$ 


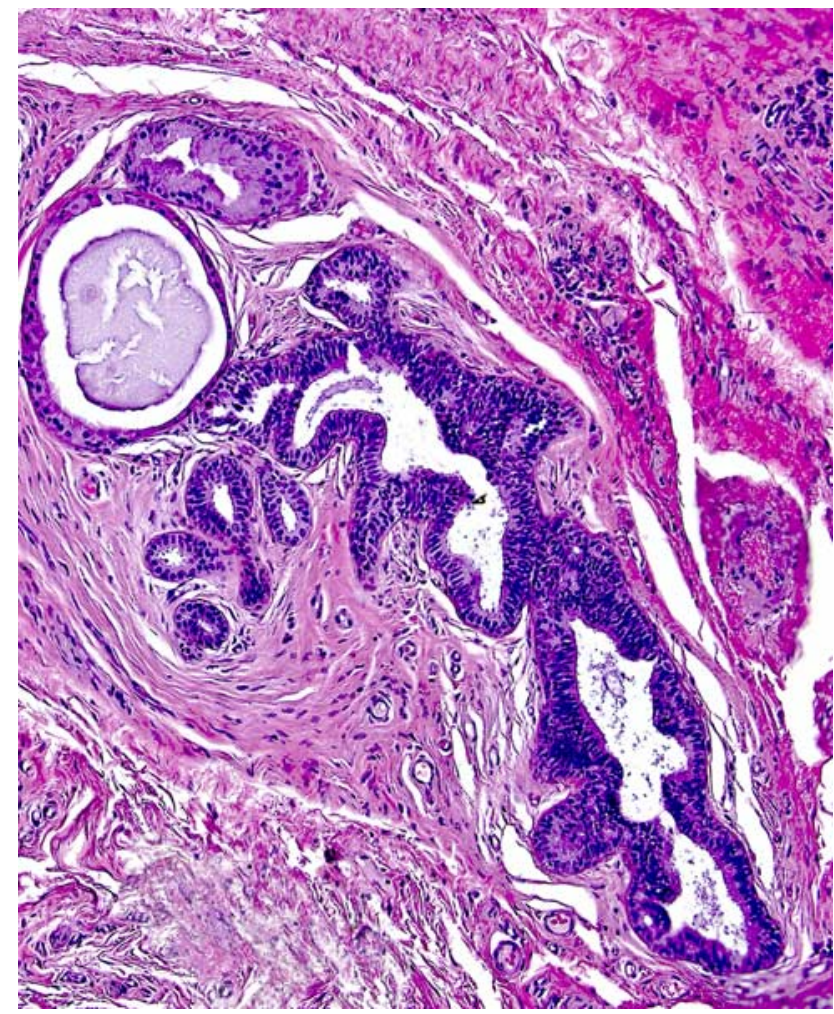

FIGURE 3. CCH of AGMLG. Note the lumina lined by $>2$ cell layers of elongated to ovoid columnar epithelial cells oriented perpendicularly to the basement membrane, having apical cytoplasmic snouts.

In this series, there were 4 cases of invasive mammary-type carcinomas of AGMLG and 3 cases of DCIS, suggesting that in these cases the carcinoma may have originated in AGMLG, with subsequent upward migration of the neoplastic cells into the epidermis, similar to cases of so-called invasive MPD. ${ }^{7,33}$ In 2 of these cases, there was elastosis near the DCIS that may be a sign of stromal invasion analogous to the situation in the breast in which an invasive carcinoma of NST may elicit prominent elastosis, at times so prominent as to be appreciated grossly as white chalky streaks. If one accepts the occurrence of DCIS and invasive carcinoma as 1 path of tumor progression in EMPD, then $\mathrm{UDH}$ and $\mathrm{ADH}$ might reasonably be interpreted as precursor lesions.

In contrast, we have previously shown that cutaneous adnexa including hair follicles, sebaceous glands, and apocrine and eccrine units may present a path for carcinomatous spread into deeper tissues in cases of EMPD, as they are involved in almost all cases. ${ }^{7,22}$ A similar situation may be presumed with respect to AGMLG. We noticed several patterns of colonization of AGMLG by neoplastic cells. Both ductal and/ or glandular components were focally or diffusely infiltrated by neoplastic cells with preservation of the normal luminal cells or, as seen in one case, there was almost complete replacement of the normal luminal
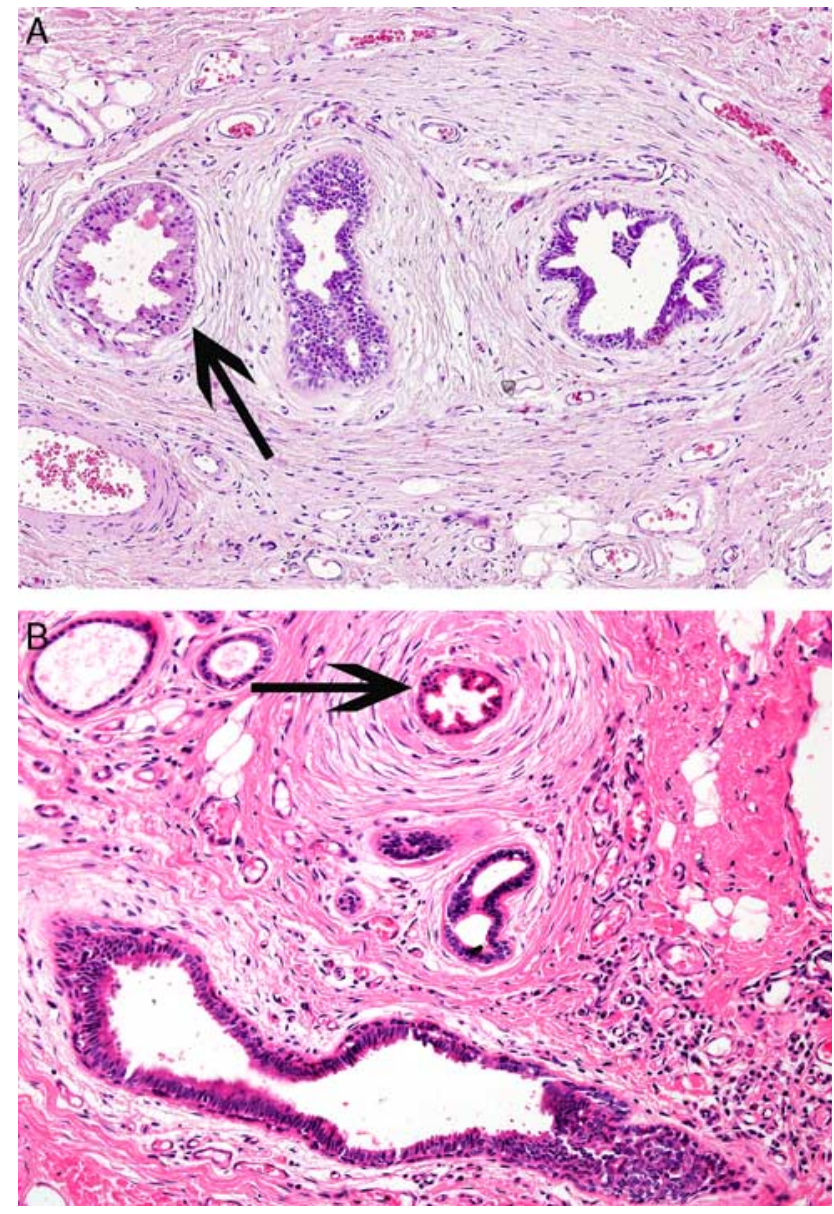

FIGURE 4. A and B, Oxyphilic metaplasia of AGMLG. Note cells with eosinophilic, glassy cytoplasm in 2 glands (arrows).

epithelium by solid or cribriform formations of Paget cells above a preserved peripheral myoepithelial cell layer resembling DCIS. In the latter case, it may be difficult or impossible to determine whether DCIS is the source of the EMPD or the result of colonization of these glands by the neoplastic cells of EMPD. Although we arbitrarily considered single cell spread of Paget cells in AGMLG as colonization, we cannot completely exclude that this may be an incipient (in situ) carcinomatous change within AGMLG or the result of a field effect. One can argue that the similar occurrence in cutaneous adnexa may occasion the same conclusion, but the absence of lesions compatible with DCIS in eccrine/apocrine units and involvement of different adnexa (sebaceous glands, hair follicles, etc.) militate against an adnexal origin.

In conclusion, AGMLG in primary EMPD manifest a range of changes analogous to those occurring in the breast and which may be regarded as a morphologic spectrum. As $\mathrm{CCC}$ and $\mathrm{CCH}$ may be encountered in normal AGMLG, these alterations would seem to play little, if any, role in the pathogenesis of EMPD. 

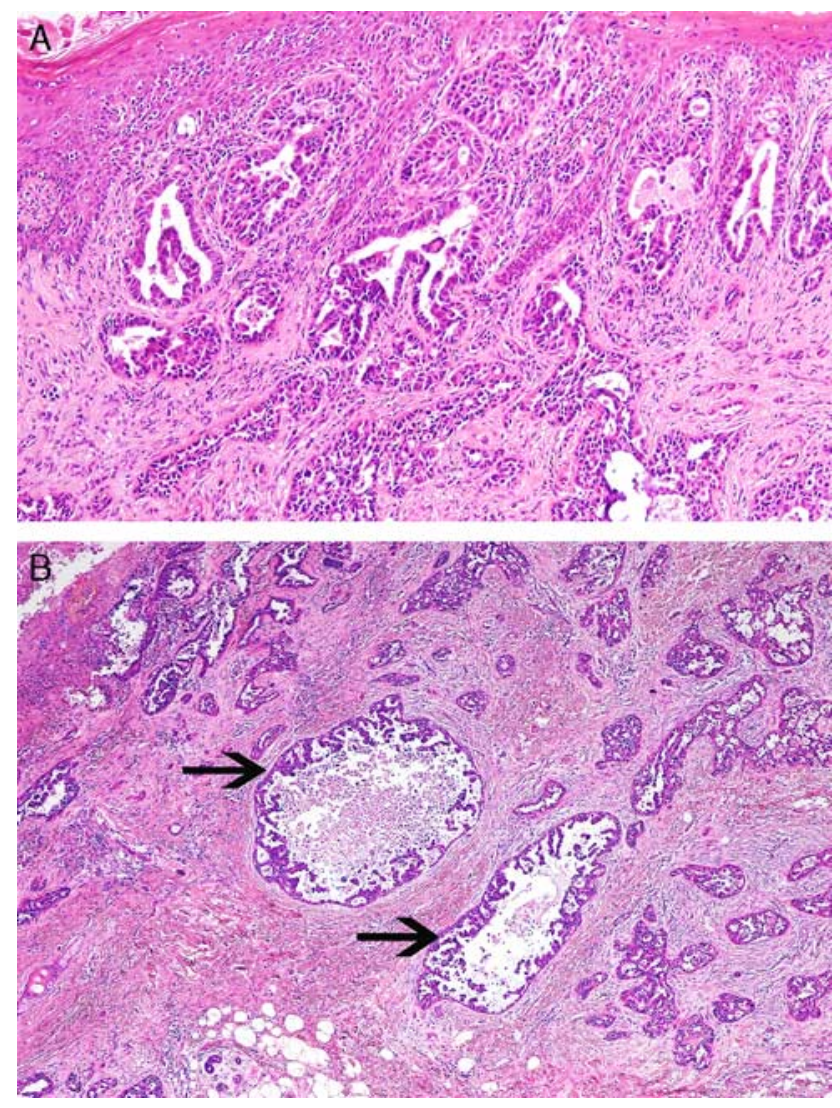

FIGURE 5. EMPD associated with underlying mammary-type invasive carcinoma of NST (previously called invasive ductal carcinoma) (A). Note DCIS of micropapillary type (arrows) (B).

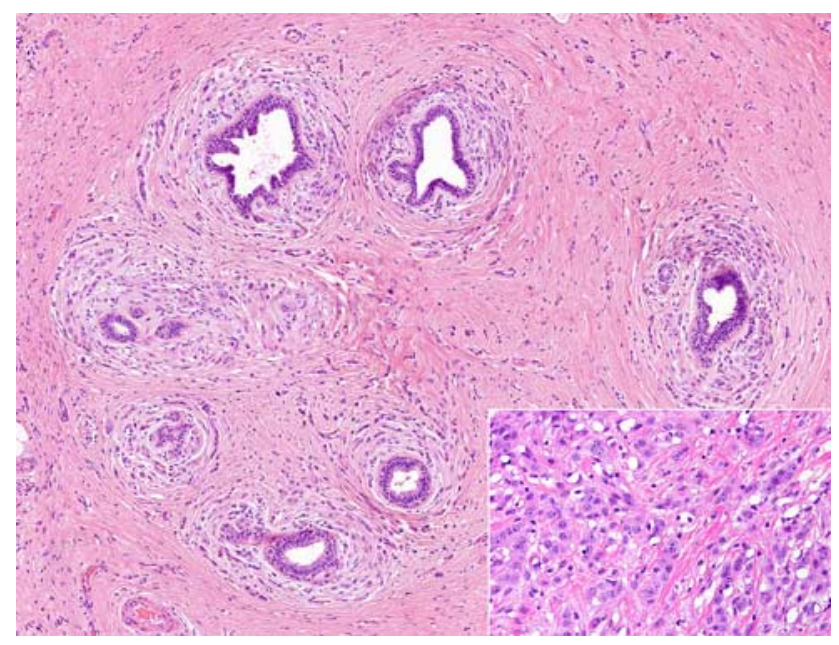

FIGURE 6. Formations of invasive tubulolobular carcinoma concentrically surrounding AGMLG with CCC. The invasive carcinoma in other areas was composed of single cell cords of round to ovoid cells intermixed with round to elongated tubules showing decapitation secretion at the luminal border, with both components positive for E-Cadherin (not shown). Inset: higher magnification of the invasive component.
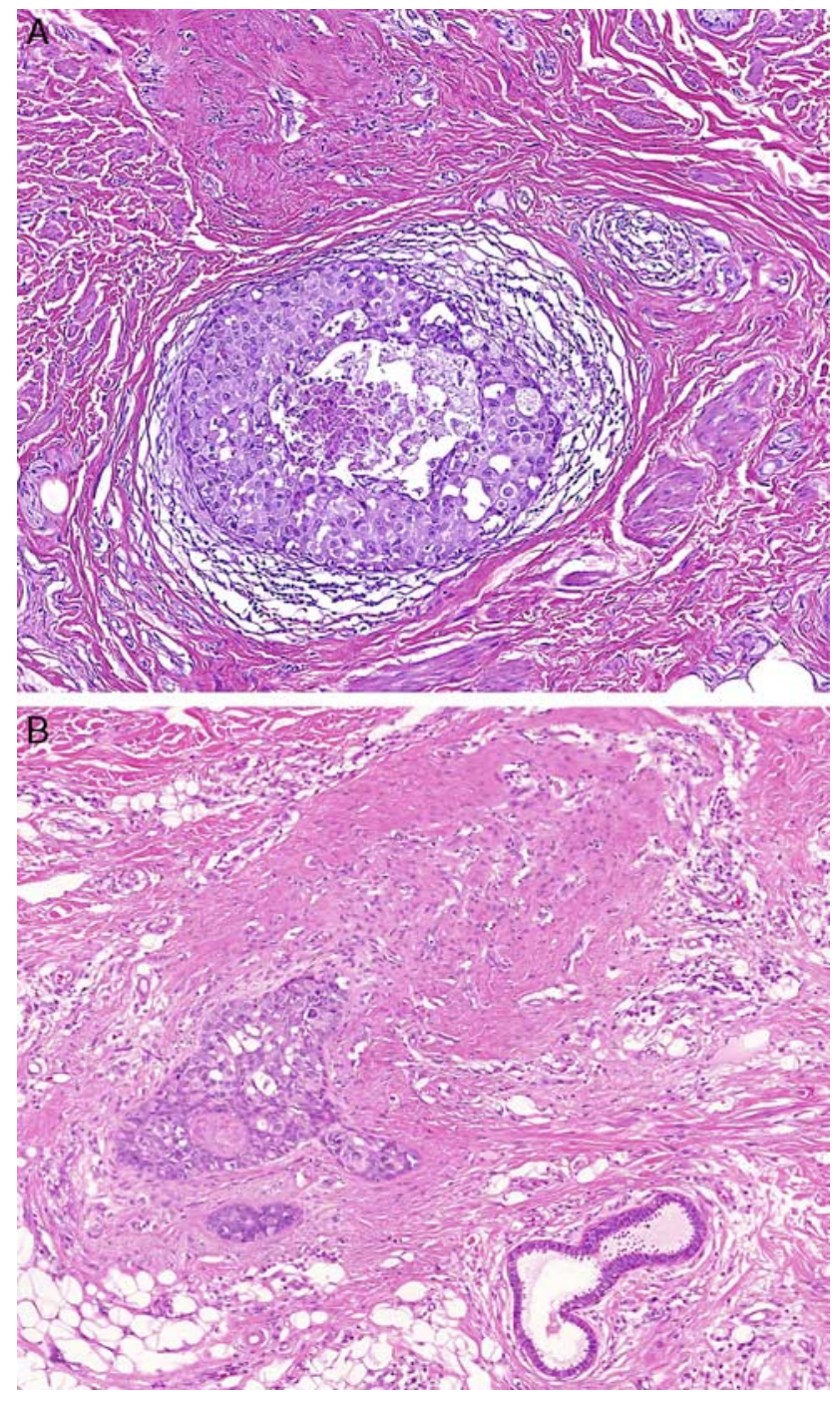

FIGURE 7. $A$ and $B$, DCIS of solid type involving AGMLG with adjacent areas of fibrosis and elastosis. Note possible microinvasion (B).

However, DCIS and invasive carcinoma comprising the malignant end of the spectrum suggest, by analogy with some cases of MPD, ${ }^{33}$ that rare cases of primary EMPD may originate in AGMLG with subsequent upward migration of the neoplastic cells into the epidermis and possible later breach through the basement membrane. UDH and ADH can then be regarded as precursor lesions, linking both ends of the spectrum. If our proposition is confirmed in subsequent studies, this may result in a reevaluation of current therapeutic approaches to primary EMPD, especially with respect to local surgical and nonsurgical treatment, which should take into consideration both the depth of secondary adnexal involvement (up to $3.6 \mathrm{~mm}$ ) and the depth of location of AGMLG (up to $3.9 \mathrm{~mm}$ ) as a possible source of disease, including recurrences, which have a rate that ranges currently from $12 \%$ to $57 \% .^{3,22,32}$ 

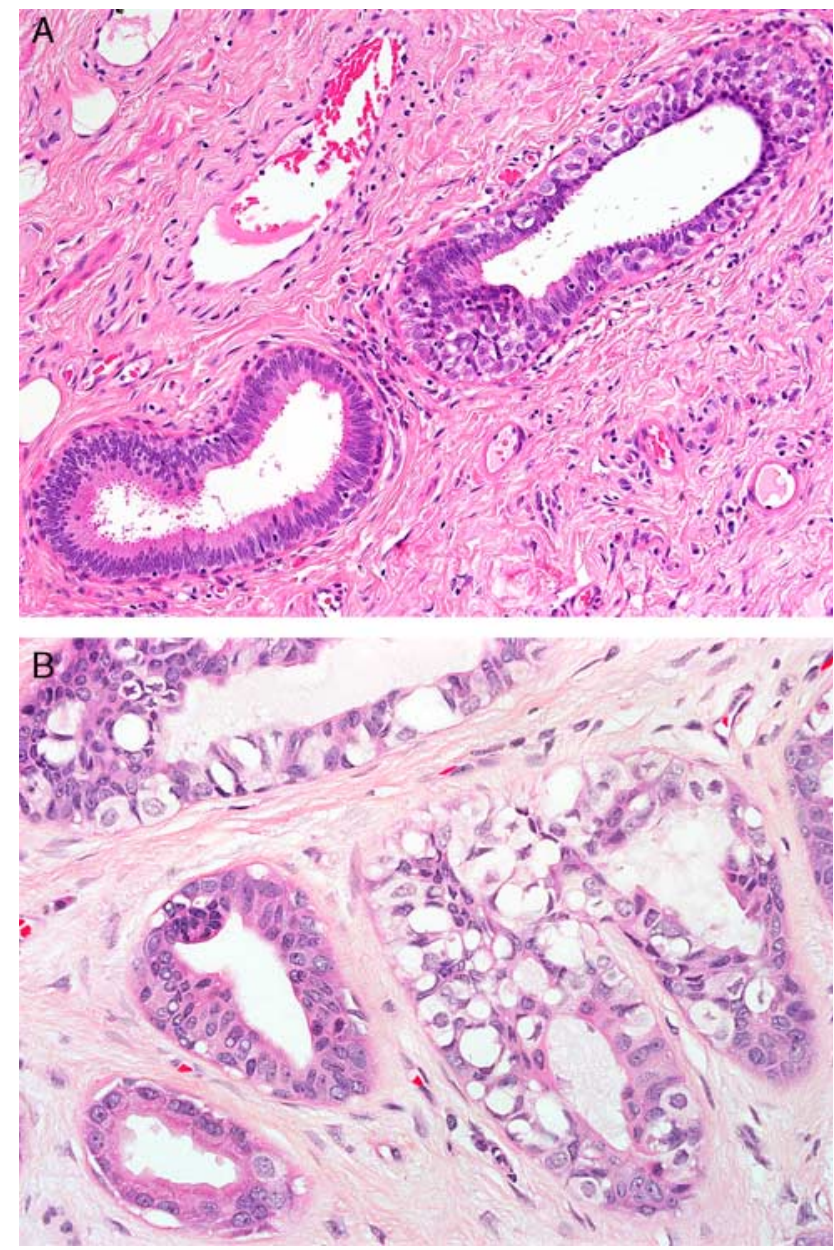

FIGURE 8. Colonization of AGMLG by Paget cells. Note the diffuse infiltration of the duct and CCC (A), and diffuse colonization of the glands (B).

\section{REFERENCES}

1. Lam C, Funaro D. Extramammary Paget's disease: summary of current knowledge. Dermatol Clin. 2010;28:807-826.

2. Kazakov DV, Spagnolo DV, Kacerovska D, et al. Lesions of anogenital mammary-like glands: an update. Adv Anat Pathol. 2011; 18:1-28.

3. Kazakov DV, Michal M, Kacerovska D, et al. Cutaneous Adnexal Tumors. Philadelphia, PA: Lippincott Williams \& Wilkins; 2012.

4. Parker LP, Parker JR, Bodurka-Bevers D, et al. Paget's disease of the vulva: pathology, pattern of involvement, and prognosis. Gynecol Oncol. 2000;77:183-189.

5. Weedon D. Weedon's Skin Pathology, 3rd ed. London: Churchill Livingstone Elsevier; 2010.

6. van der Putte SC. Clear cells of Toker in the developing anogenital region of male and female fetuses. Am J Dermatopathol. 2011;33: 811-818.

7. Belousova IE, Kazakov DV, Michal M, et al. Vulvar Toker cells: the long-awaited missing link: a proposal for an origin-based histogenetic classification of extramammary paget disease. $\mathrm{Am} J$ Dermatopathol. 2006;28:84-86.

8. Willman JH, Golitz LE, Fitzpatrick JE. Vulvar clear cells of Toker: precursors of extramammary Paget's disease. Am J Dermatopathol. 2005;27:185-188.

9. Toker C. Clear cells of the nipple epidermis. Cancer. 1970;25: 601-610.
10. Guarner J, Cohen C, DeRose PB. Histogenesis of extramammary and mammary Paget cells. An immunohistochemical study. Am J Dermatopathol. 1989;11:313-318.

11. Hamm H, Vroom TM, Czarnetzki BM. Extramammary Paget's cells: further evidence of sweat gland derivation. J Am Acad Dermatol. 1986;15:1275-1281.

12. Helm KF, Goellner JR, Peters MS. Immunohistochemical stains in extramammary Paget's disease. Am J Dermatopathol. 1992;14: 402-407.

13. Lloyd J, Flanagan AM. Mammary and extramammary Paget's disease. J Clin Pathol. 2000;53:742-749.

14. Mazoujian G, Pinkus GS, Haagensen DE Jr. Extramammary Paget's disease - evidence for an apocrine origin. An immunoperoxidase study of gross cystic disease fluid protein-15, carcinoembryonic antigen, and keratin proteins. Am J Surg Pathol. 1984;8:43-50.

15. Merot Y, Mazoujian G, Pinkus G, et al. Extramammary Paget's disease of the perianal and perineal regions. Evidence of apocrine derivation. Arch Dermatol. 1985;121:750-752.

16. Nadji M, Morales AR, Girtanner RE, et al. Paget's disease of the skin. A unifying concept of histogenesis. Cancer. 1982;50:2203-2206.

17. Ordonez NG, Awalt H, Mackay B. Mammary and extramammary Paget's disease. An immunocytochemical and ultrastructural study. Cancer. 1987;59:1173-1183.

18. Urabe A, Matsukuma A, Shimizu N, et al. Extramammary Paget's disease: comparative histopathologic studies of intraductal carcinoma of the breast and apocrine adenocarcinoma. J Cutan Pathol. 1990;17:257-265.

19. Di Bonito L, Patriarca S, Falconieri G. Aggressive "breast-like" adenocarcinoma of vulva. Pathol Res Pract. 1992;188:211-216.

20. Ohira S, Itoh K, Osada K, et al. Vulvar Paget's disease with underlying adenocarcinoma simulating breast carcinoma: case report and review of the literature. Int J Gynecol Cancer. 2004;14: $1012-1017$.

21. Piura B, Gemer O, Rabinovich A, et al. Primary breast carcinoma of the vulva: case report and review of literature. Eur J Gynaecol Oncol. 2002;23:21-24.

22. Konstantinova AM, Shelekhova KV, Stewart CJ, et al. Depth and patterns of adnexal involvement in primary extramammary (anogenital) Paget disease: a study of 178 lesions from 146 patients. Am J Dermatopathol. 2016;38:802-808.

23. Rosai J. Rosai and Ackerman's Surgical Pathology, 9th ed. St. Louis, MO: Elsevier Mosby; 2004.

24. Rosen P. Rosen's Breast Pathology, 3rd ed. Philadelphia, PA: Lippincott Williams \& Wilkins; 2009.

25. Lakhani S, Ellis I, Schnitt S, et al. World Health Organization Classification of Tumours of the Breast. Lyon: IARC Press; 2012.

26. Lester SC, Bose S, Chen YY, et al. Protocol for the examination of specimens from patients with invasive carcinoma of the breast. Arch Pathol Lab Med. 2009;133:1515-1538.

27. Konstantinova AM, Hayes MM, Stewart CJ, et al. Syringomatous structures in extramammary Paget disease: a potential diagnostic pitfall. Am J Dermatopathol. 2016;38:653-657.

28. Konstantinova AM, Kacerovska D, Stewart CJ, et al. Syringocystadenocarcinoma papilliferum in situ-like changes in extramammary Paget disease: a report of 11 cases. Am J Dermatopathol. 2016;38: 882-886.

29. Konstantinova AM, Michal M, Kacerovska D, et al. Hidradenoma papilliferum: a clinicopathologic study of 264 tumors from 261 patients, with emphasis on mammary-type alterations. Am J Dermatopathol. 2016;38:598-607.

30. Feuer GA, Shevchuk M, Calanog A. Vulvar Paget's disease: the need to exclude an invasive lesion. Gynecol Oncol. 1990;38:81-89.

31. Dabbs DJ, Carter G, Fudge M, et al. Molecular alterations in columnar cell lesions of the breast. Mod Pathol. 2006;19:344-349.

32. Konstantinova AM, Kyrpychova L, Belousova IE, et al. Anogenital mammary-like glands: a study of their normal histology with emphasis on glandular depth, presence of columnar epithelial cells and distribution of elastic fibers. Am J Dermatopathol. 2016; In press.

33. Duan X, Sneige N, Gullett AE, et al. Invasive paget disease of the breast: clinicopathologic study of an underrecognized entity in the breast. Am J Surg Pathol. 2012;36:1353-1358. 